\title{
Synthesis, plasmonic properties, and CWA simulant decontamination activity of first row early transition metal nitride powders and nanomaterials
}

\author{
Andrew P. Purdy ${ }^{1}$ (D . Olga A. Baturina ${ }^{1} \cdot$ Blake S. Simpkins $^{1} \cdot$ Spencer Giles ${ }^{1} \cdot$ Todd Brintlinger $^{2} \cdot$ James Wynne ${ }^{1}$
}

Received: 3 February 2020 / Accepted: 30 March 2020 / Published online: 11 April 2020

(c) This is a U.S. Government work and not under copyright protection in the U.S.; foreign copyright protection may apply 2020

\begin{abstract}
The complexes $\mathrm{MCl}_{3}(\mathrm{THF})_{3}(\mathrm{M}=\mathrm{Ti}, \mathrm{V}, \mathrm{Cr})$ were used as precursors to form early transition metal nitrides, and solid solutions of these isomorphous complexes $\mathrm{M}_{\mathrm{x}} \mathrm{M}_{1-\mathrm{x}} \mathrm{Cl}_{3}(\mathrm{THF})_{3}$ were prepared by co-crystallization. Heating the precursor under $\mathrm{NH}_{3}$ flow from 800 to $950^{\circ} \mathrm{C}$ produced powders of the nitride $\mathrm{MN}$, and solid solutions of these precursors produced alloys of the nitrides. Nanomaterials were synthesized by two methods: (1) reaction of a $\mathrm{MCl}_{3}(\mathrm{THF})_{3}$ solution with 3 eq of $\mathrm{KNH}_{2}$ in THF in the presence (or absence) of oleylamine, followed by nitridation under $\mathrm{NH}_{3}$ flow at $650-950^{\circ} \mathrm{C}$ and (2) loading a porous catalyst support such as pelletized $\mathrm{Al}_{2} \mathrm{O}_{3}$ with the $\mathrm{MCl}_{3}(\mathrm{THF})_{3}$ complex, followed by similar heat treatment. The materials were characterized by powder X-ray diffraction, elemental analysis, SEM, and optical spectroscopy. Diffuse reflectance and UV-Vis-NIR spectroscopy showed the local surface plasmonic resonances (LSPRs). Although diffuse reflectance and UV-Vis-NIR spectroscopy showed LSPRs whose position was sensitive to surface functionalization and conditions of preparation, preliminary results show TiN nanoparticles have some activity in the degradation of the Chemical Warfare Agent (CWA) simulant DEMETON-S, but light plays no role in the mechanism.
\end{abstract}

Keywords Titanium nitride · Plasmon · Solid solutions, nanomaterials, demeton-S · Refractory plasmonics

\section{Introduction}

Some early transition metal nitrides, particularly TiN and $\mathrm{ZrN}$, have optical properties similar to noble metals (e.g., $\mathrm{Au}, \mathrm{Ag})$, making them potential drop-in replacements for these expensive and, in some cases, chemically unstable materials. In fact, TiN has been shown to exhibit plasmonic resonances similar to those of Au but at a far reduced cost and with much greater thermal stability [1-7]. Additionally, there is already a fair body of literature that already describes the use of hot charge carriers, generated via plasmon decay [8], to perform a number of reactions [9], including water oxidation [10,11], water reduction [12-14], oxidation of amines to aldehydes [15], $\mathrm{CO}_{2}$ reduction [16], and $\mathrm{NH}_{3}$ decomposition [17]. Typically, these demonstrations have utilized Au plasmonic nanoparticles on a semiconducting support, [18] often $\mathrm{TiO}_{2}$ [19]. These metal-semiconductor heterosystems may serve to enhance charge separation as well as promote the reaction of interest if a catalytic semiconductor is used. In the

Electronic supplementary material The online version of this article (https://doi.org/10.1007/s42452-020-2648-9) contains supplementary material, which is available to authorized users.

Andrew P. Purdy, andrew.purdy@nrl.navy.mil | 'US Naval Research Laboratory, Chemistry Division Code 6100, Washington, DC 20375-5342, USA. ${ }^{2}$ US Naval Research Laboratory, Materials Division Code 6300, Washington, DC 20375-5342, USA. 
present work, ${ }^{1}$ we prepared nanomaterials of the first row early transition metal nitrides, and their solid solutions, and tested select variants for activity in degradation of the Chemical Warfare Agent (CWA) simulant Demeton-S. We are operating under the presumption that a thin layer of $\mathrm{TiO}_{2}$ is present on all TiN particles that have been exposed to air, and this will be the surface upon which reactions occur.

\section{Experimental}

\subsection{General comments}

All solvents for organometallic synthesis were dried from either sodium (toluene), sodium benzophenone ketyl (THF) or $\mathrm{P}_{2} \mathrm{O}_{5}\left(\mathrm{CH}_{2} \mathrm{Cl}_{2}\right)$ and distilled before use. Solvents for Demeton-S experiments were not dried. All manipulations of anhydrous metal chlorides and organometallic complexes were done under inert atmosphere (argon) in a recirculating dry box or under $\mathrm{N}_{2}$ in a flow box, but once converted to metal nitrides, the products were handled in air. $\mathrm{KNH}_{2}$ was made from a reaction between $\mathrm{K}$ and $\mathrm{NH}_{3}$ in a stainless steel cylinder. Powder XRD patterns were recorded on a Rigaku SmartLab 2080B212 3 kW powder $\mathrm{X}$-ray diffractometer with $\mathrm{Cu}$ Ka radiation, and BET measurements were obtained on an Micromeritics ASAP 2020. Visible light absorption of synthesized nanoparticles, and $\mathrm{Y}-\mathrm{Al}_{2} \mathrm{O}_{3}$ supported TiN and Au powders were characterized by UV-Vis spectra, which were collected on water or methanol dispersions in transmission mode, and in diffuse reflectance mode for powdered samples, using a PerkinElmer UV/VIS/NIR $\lambda 1050$ spectrometer. Powdered samples were diluted to $3 \mathrm{wt} \%$ with $\mathrm{KBr}$ prior to collecting diffuse reflectance spectra, and an integrated sphere was used. X-ray photoelectron spectroscopy (XPS) was done on a Thermo-Fisher Nexsa instrument.

\subsection{Synthesis of $\mathrm{MCl}_{3}[\mathrm{THF}]_{3}$}

Complexes were prepared in a similar manner to [20-22]. (a) $\mathrm{M}=\mathrm{Ti} 50 \mathrm{~mL}$ THF was slowly added to $10 \mathrm{~g} \mathrm{TiCl} 3\left(\mathrm{AlCl}_{3}\right)_{1 / 3}$ (Aldrich) in $150 \mathrm{~mL}$ toluene in the dry box and stirred until fully reacted, and mixture was heated to dissolve. When the mixture had cooled, it was filtered and the blue crystals were washed with more a toluene-THF mixture and

\footnotetext{
1 Part of this work was presented at the 254th ACS National Meeting \& Exposition, Washington, DC, USA, August 20, 2017. Purdy, A P.; Baturina, OA.; Simpkins, B; Giles, SL, Synthesis and plasmonic properties of early transition metal nitride powders and nanomaterials. INOR 55.
}

a small amount of THF and pumped dry, affording $17.3 \mathrm{~g}$ $\mathrm{TiCl}_{3}(\mathrm{THF})_{3}$ (93\%). (b) $\mathrm{VCl}_{3}(10.79 \mathrm{~g})$ was mixed with $150 \mathrm{~mL}$ THF and heated at $70^{\circ} \mathrm{C}$ for 3 days. Toluene added at room temperature and pink crystals were isolated by filtration and pumped dry. $22.81 \mathrm{~g}$ (89\%) isolated. (c) Anhydrous $\mathrm{CrCl}_{3}(7.5 \mathrm{~g}, 47.3 \mathrm{mmol})$ was mixed with $50 \mathrm{~mL} \mathrm{THF}, 20 \mathrm{~mL}$ $\mathrm{CH}_{2} \mathrm{Cl}_{2}$, and a pinch of $\mathrm{Zn}$ dust and was agitated in the flow box until the exotherm had subsided, and then was sonicated for $15 \mathrm{~min}$ and filtered in the flow box. The filtrate was pumped to dryness, affording $15.166 \mathrm{~g}(86 \%)$ $\mathrm{CrCl}_{3}(\mathrm{THF})_{3}$. (d) Except for A5, mixed solid solutions were prepared by combining portions of the individual metal complexes in $\mathrm{CH}_{2} \mathrm{Cl}_{2}$, and allowing the solution to slowly evaporate in the $\mathrm{N}_{2}$ flow box to afford crystals of mixtures. The precursor for $\mathbf{A} \mathbf{5}$ was made by dissolving the Ti and V salts in hot THF and allowing to cool.

\subsection{Preparation of nanoparticle precursors}

Three different types of precursors were used for $\mathrm{MN}$ nanoparticles, and the specific conditions for each sample are listed in Table 1. All materials with the exception of the final product were handled under inert atmosphere. On all cases, the final product was washed with water to remove salts and with ethanol and dried. For the (A) samples, the $\mathrm{MCl}_{3}(\mathrm{THF})_{3}$ complex (either single metal or mixtures prepared as described above) was directly placed in an $\mathrm{Al}_{2} \mathrm{O}_{3}$ boat inside a tube furnace. In one instance, a quartz slide was placed near the boat and a film of VN was deposited on the slide, in addition to the powders. (B) $\mathrm{TiCl}_{3}(\mathrm{THF})_{3}(1.01 \mathrm{~g}, 2.72 \mathrm{mmol})$ was mixed with $\mathrm{KNH}_{2}$ $(0.465 \mathrm{~g}, 8.43 \mathrm{mmol})$ in about $30 \mathrm{~mL}$ of THF in a bulb with a Kontes teflon valve. The bulb was sonicated overnight and the solvent pumped off, affording $0.827 \mathrm{~g}$ precursor. $\mathrm{A} \sim 50 \%$ portion of this solid was placed in an $\mathrm{Al}_{2} \mathrm{O}_{3}$ boat in a tube furnace and heated as described below. After washing with water and drying, $106 \mathrm{mg} \mathrm{TiN} \mathrm{(B1)} \mathrm{was} \mathrm{iso-}$ lated. (C) $\mathrm{MCl}_{3}(\mathrm{THF})_{3}$ was mixed with $\mathrm{KNH}_{2}$ and oleylamine in $\sim 40 \mathrm{~mL} \mathrm{THF}$, with the amounts used in each case listed in Table 1. The bulb was sonicated for several hours, heated overnight at $80^{\circ} \mathrm{C}$, and filtered in drybox. The black precursor powder was loaded into the $\mathrm{Al}_{2} \mathrm{O}_{3}$ boat and heated as described below.

\subsection{Conversion of precursor into nanomaterials, series $A, B, C$}

The precursor was loaded into an alumina boat, which was inserted into a quartz tube under inert atmosphere. The tube was placed in a tube furnace under flowing $\mathrm{NH}_{3}$, the temperature was first increased to an intermediate temperature of $200-250^{\circ} \mathrm{C}$ for about $1 \mathrm{~h}$, then a higher intermediate temperature of $350-450^{\circ} \mathrm{C}$ for about an hour 
Table 1 Synthesis conditions and results for MN nanomaterials

Intermediate temps $\left({ }^{\circ} \mathrm{C}\right) \quad$ Final temp $\left({ }^{\circ} \mathrm{C}\right.$, time $)$ Yield $(\mathrm{g})$

$\operatorname{BET}\left(\mathrm{m}^{2} / \mathrm{g}\right) \quad$ XRD (phase; crystallite size $\left.^{*}\right)$

Method A

Precursor $\left[\mathrm{MCl}_{3}(\mathrm{THF})_{3}\right]$

(g)

$\begin{array}{llllll}\text { A1 Ti }(0.54) & 250,400,650^{\circ} \mathrm{C} & 85016 \mathrm{~h} & 0.074(82 \%) & 20.73 & \mathrm{TiN} ; 30 \mathrm{~nm} \\ \text { A2 V (2.04) } & 200,450 & 9001 \mathrm{~h} & 0.34(96 \%) & 7.16 & \mathrm{VN} ; 42 \mathrm{~nm} \\ \text { A3 V }(0.76) & 200.450 & 9002 \mathrm{~h} & 0.13(98 \%) & 0.29^{* * *} & \mathrm{VN} ; 60 \mathrm{~nm} \\ \text { A4 } \mathrm{Cr}(1.035) & 250,450 & 8502 \mathrm{~h} & 0.17(93 \%) & 0.33^{* * *} & \mathrm{CrN} ; 60 \mathrm{~nm}, \mathrm{Cr}_{2} \mathrm{~N} ; 53 \mathrm{~nm} \\ \text { A5 } \operatorname{Ti}-\mathrm{V}(1.34) & 250,450 & 8501 \mathrm{~h} & 0.19(83 \%) & 34.42 & \mathrm{MN} ; 15 \mathrm{~nm} \\ \text { A6 } \operatorname{Ti}-\operatorname{Cr}(0.99) & 200,450 & 8502 \mathrm{~h} & 0.12(71 \%) & 0.67 * * * & \mathrm{MN} ; 19 \mathrm{~nm}, \mathrm{M}_{2} \mathrm{~N} \\ \text { A7 } \operatorname{Ti}-\mathrm{V}-\operatorname{Cr}(1.50) & 200,450 & 8502 \mathrm{~h} & 0.22(85 \%) & 7.67 & \mathrm{MN} ; 25 \mathrm{~nm}\end{array}$

Method B

$\left[\mathrm{TiCl}_{3}(\mathrm{THF})_{3}\right], \mathrm{KNH}_{2}$

**B1 $1.01 \mathrm{~g}, 0.465 \mathrm{~g}$

$\mathrm{KNH}_{2}$

150,250

$850^{\circ} \mathrm{C} 16 \mathrm{~h}$

0.106 (50\% of precursor)

45.40

$\mathrm{TiN} ; 15 \mathrm{~nm}$

Method C

$\mathrm{MCl}_{3}(\mathrm{THF})_{3} ; \mathrm{KNH}_{2}$;

$\mathrm{OA}(\mathrm{g})$

**C1 M=Ti 2.02; 0.92; 200,350

$0.17 \sim 50 \%$ portion

$201.72 \quad \mathrm{TiN} ; 6 \mathrm{~nm}$

**C1a

200

$6501 \mathrm{~h}$

C2 (Ti-V-Cr) Ti 0.74 V

250,350

$8501 \mathrm{~h}$

$0.18 \sim 50 \%$ portion

183.55

$\mathrm{TiN} ; 4 \mathrm{~nm}$

$0.77 \mathrm{Cr} 0.811 .03$

$\mathrm{KNH}_{2} ; 1.23 \mathrm{~g} \mathrm{OA}$

C3 V $1.99 ; 0.89 ; 1.28$

250,350

$8501 \mathrm{~h}$

0.42

174.53

$\mathrm{MN} ; 6 \mathrm{~nm}$

OA

C4 $\mathrm{Cr} 1.57 ; 0.70 ; 1.28$

$\mathrm{OA}$

200,450

850 1/2h

0.31

101.68

$\mathrm{VN} ; 18 \mathrm{~nm}$

C5 $\mathrm{Cr} 1.24 ; 0.55 ; 1.2$

$\mathrm{OA}$

250.350

$8001 \mathrm{~h}$

0.25

139.68

CrN; $11 \mathrm{~nm}$, carbides, carbonitrides

57.03 $\mathrm{CrN} ; 19 \mathrm{~nm}, \mathrm{Cr}_{2} \mathrm{O}_{3}$

OA oleylamine

*Determined by Rigaku PDXL-2 software v 2.0.3.0 using Halder-Wagner method

${ }^{* *}$ Only a $50 \%$ portion of precursor used

***Insufficient sample for accurate reading—surface area too low

and then the final temperature of typically $800-900^{\circ} \mathrm{C}$ for 1 or more hours. The conditions for each sample are listed in Table 1.

\subsection{Impregnation of oxide catalyst support pellets (series D)}

(a) Pelletized $\mathrm{\gamma}-\mathrm{Al}_{2} \mathrm{O}_{3}$ (Alfa \#43,832) was heated under dynamic vacuum at $550^{\circ} \mathrm{C}$ until no more gas was evolved, and allowed to cool. In the dry box, $0.993 \mathrm{~g}$ dried $\mathrm{Al}_{2} \mathrm{O}_{3}$ pellets was mixed with $\mathrm{TiCl}_{3}(\mathrm{THF})_{3}(0.751 \mathrm{~g})$ and dry $\mathrm{CH}_{2} \mathrm{Cl}_{2}$ was added. After several hours, the solution was decanted and the pellets washed with a small amount of $\mathrm{CH}_{2} \mathrm{Cl}_{2}$. The impregnated pellets were pumped dry and then heated in a tube furnace under $\mathrm{NH}_{3}$ flow at $250^{\circ} \mathrm{C}$ for $0.5 \mathrm{~h}$, then at $450^{\circ} \mathrm{C}$ for $16 \mathrm{~h}$ and at $900^{\circ} \mathrm{C}$ for $3 \mathrm{~h}$. Total mass of impregnated pellets (D1) is $1.075 \mathrm{~g}$ (weight gain 7.62\%). (b) Dry $\mathrm{Al}_{2} \mathrm{O}_{3}$ pellets $(0.603 \mathrm{~g}$ ) was mixed with $1.00 \mathrm{~g}$ of $\mathrm{HAuCl}_{4}$ solution $(0.1469 \mathrm{M})$ and let dry at about $50^{\circ} \mathrm{C}$, and heated under $\mathrm{H}_{2}$ flow in tube furnace at $250^{\circ} \mathrm{C}$ for $1 \mathrm{~h}$ and $500{ }^{\circ} \mathrm{C}$ for $2 \mathrm{~h}$, affording purplish colored pellets (D2) with mass $0.6181 \mathrm{~g}$ (weight gain $2.44 \%$ ).

\subsection{Chemical agent simulant decontamination challenge}

Synthesized titanium nitride (C1) and titanium nitride impregnated in $\gamma$-alumina (D1) were challenged with CWA simulant Demeton-S (S-(2-Ethylthioethyl) O,Odimethyl phosphorothioate). Demeton-S was deposited onto these substrates from a stock solution composed of $10.5 \mu \mathrm{L}\left(4.66 \times 10^{-5} \mathrm{~mol}\right)$ Demeton- $\mathrm{S}$ in $2 \mathrm{~mL}$ of methylene 
Table 2 Mass of individual catalysts challenged with Demeton-S

\begin{tabular}{llll}
\hline Catalyst & $\begin{array}{l}\text { 0 h Exposure } \\
(\mathrm{mg})\end{array}$ & $\begin{array}{l}6 \mathrm{~h} \text { exposure } \\
(\mathrm{mg})\end{array}$ & $\begin{array}{l}24 \mathrm{~h} \\
\text { exposure } \\
(\mathrm{mg})\end{array}$ \\
\hline Control-1 & 0 & 0 & 0 \\
Control-2 & 0 & 0 & 0 \\
TiN-1 & 1.67 & 1.28 & 1.13 \\
TiN-2 & 0.83 & 1.13 & 0.96 \\
TiN- $-\mathrm{Al}_{2} \mathrm{O}_{3}-1$ & 1.48 & 1.10 & 1.90 \\
TiN-Al $\mathrm{O}_{3}-2$ & 2.32 & 1.40 & 1.30 \\
\hline
\end{tabular}

chloride $\left(\mathrm{CH}_{2} \mathrm{Cl}_{2}\right)$. Depositions consisted of $20 \mu \mathrm{L}$ of the stock solution deposited onto the solid substrates of various masses (Table 2) contained in a $200 \mu \mathrm{L} \mathrm{GC}$ clear glass vial inserts contained within a standard $2 \mathrm{~mL} \mathrm{GC}$ vial. After deposition the methylene chloride was allowed to evaporate $(1 \mathrm{~h})$ depositing the Demeton-S onto the surface of the nanoparticles. After solvent evaporation the GC vials were sealed and then extracted at various time intervals after the solvent evaporation was performed: immediately $(0 \mathrm{~h})$, after $6 \mathrm{~h}$ and after $24 \mathrm{~h}$. Additional control depositions were also performed into empty vial inserts and extracted at the same time intervals following the same protocol. Two extractions were performed with acetonitrile $(\mathrm{MeCN})$ in which $100 \mu \mathrm{L}$ of $\mathrm{MeCN}$ was deposited onto the nanoparticles and allowed to extract the organic products and transferred to new $2 \mathrm{~mL} \mathrm{GC}$ vials. Following the extractions $800 \mu \mathrm{L}$ of $\mathrm{MeCN}$ was added to the $\mathrm{GC}$ vial to dilute to $1000 \mu \mathrm{L}(1 \mathrm{~mL})$ prior to analysis.

Analysis for the percent reduction of Demeton-S and byproducts was performed using GC-MS. GC-MS analysis was performed using an Agilent 7890B gas chromatograph coupled with an Agilent 5977 B mass spectrometer operating in electron ionization (EI) mode and an Agilent 7693 autosampler (Agilent Technologies, Santa Clara, CA, USA). The GC-MS was equipped with a Restek 5HT capillary column (Restek Corporation, Bellefonte, PA, USA) operating in split injection mode with a split ratio of 5:1 for 1 $\mu \mathrm{L}$ injection volumes with helium carrier gas at a flow of $1.2 \mathrm{~mL} / \mathrm{min}$. The temperature program for the GC-MS had an initial temperature of $100^{\circ} \mathrm{C}$ for $1 \mathrm{~min}$ then the temperature was ramped at $20^{\circ} \mathrm{C} / \mathrm{min}$ to $130^{\circ} \mathrm{C}$ followed by a $15^{\circ} \mathrm{C} / \mathrm{min}$ ramp up to $285^{\circ} \mathrm{C}$ with a post run hold of $300^{\circ} \mathrm{C}$ for $2.5 \mathrm{~min}$. The injection temperature, MS quad temperature, and source temperature were $275,150,230^{\circ} \mathrm{C}$, respectively. The solvent delay was set to $1.75 \mathrm{~min}$ and the MS detector was set to scan from 34 to $350 \mathrm{~m} / \mathrm{z}$. The percent reduction for each challenge was calculated from the concentration of the Demeton-S deposited and the measured concentration from the samples and the controls. The concentration of Demeton-S for each challenge

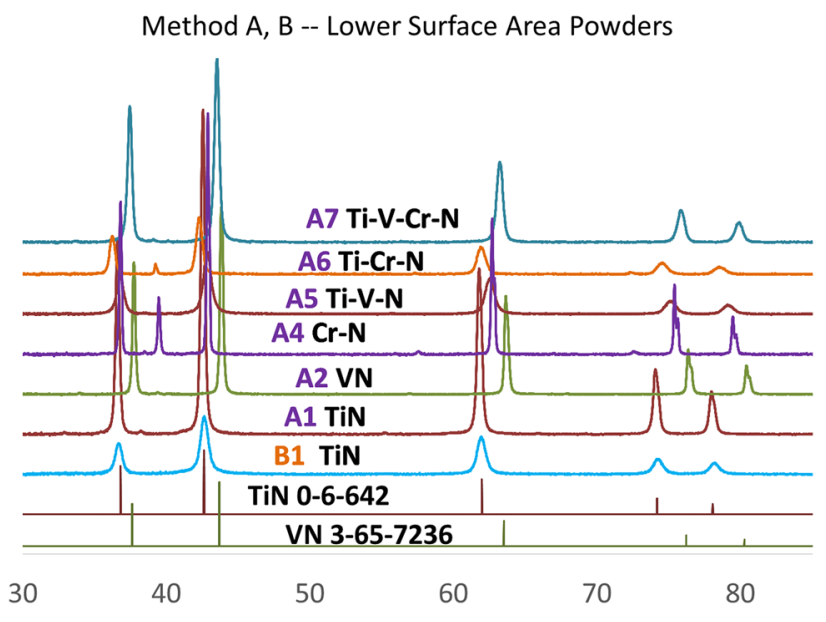

Fig. 1 X-ray powder patterns of the A and B series metal nitride materials. JCPDS reference patterns for TiN and VN indicated

and control was calculated using a calibration curve generated from known concentrations of Demeton-S (SI).

\section{Results and discussion}

\subsection{Material synthesis and characterization}

The early transition metal trichloride tris-THF adducts $\left[\mathrm{MCl}_{3}(\mathrm{THF})_{3}\right][\mathrm{M}=\mathrm{Ti}, \mathrm{V}, \mathrm{Cr}]$ are excellent precursors to bulk nanostructured metal nitrides $\mathrm{MN}$, simply by heating the precursor material in a tube furnace under flowing, anhydrous ammonia. Since the precursor has almost no vapor pressure, most of the produced nitride remains in the alumina boat in which the precursor was placed, and the yields range from 71 to $98 \%$. With the Ti and V precursors, films that are presumably metal nitride did deposit on the quartz tube and the alumina boat containing the precursor. As a test of film growth, in one instance (A3), a quartz slide was placed with the boat and a film of VN was deposited on the slide. All of the nitride products are single phase except with $\mathrm{Cr}$, where some powder XRD peaks for $\mathrm{Cr}_{2} \mathrm{~N}$ were evident (Fig. 1). Additionally, all of the trichloride precursors have similar crystal structures and solubilities in $\mathrm{CH}_{2} \mathrm{Cl}_{2}$, and crystals of mixed precursors were easily prepared by slowly evaporating a $\mathrm{CH}_{2} \mathrm{Cl}_{2}$ solution of the precursors under inert atmosphere conditions. Those crystals were converted into nitrides in the same manner, and produced single phase MN as determined by $X R D$, except in the case of $\mathbf{A 6}$, which had a high fraction of $\mathrm{Cr}$. The XRD patterns are shown in Fig. 1. Typically, the line widths of materials produced from a single metal were much narrower than those produced from a mixture of metals, indicating larger crystallite sizes in the single metal cases. However, the morphology of the metal nitrides 

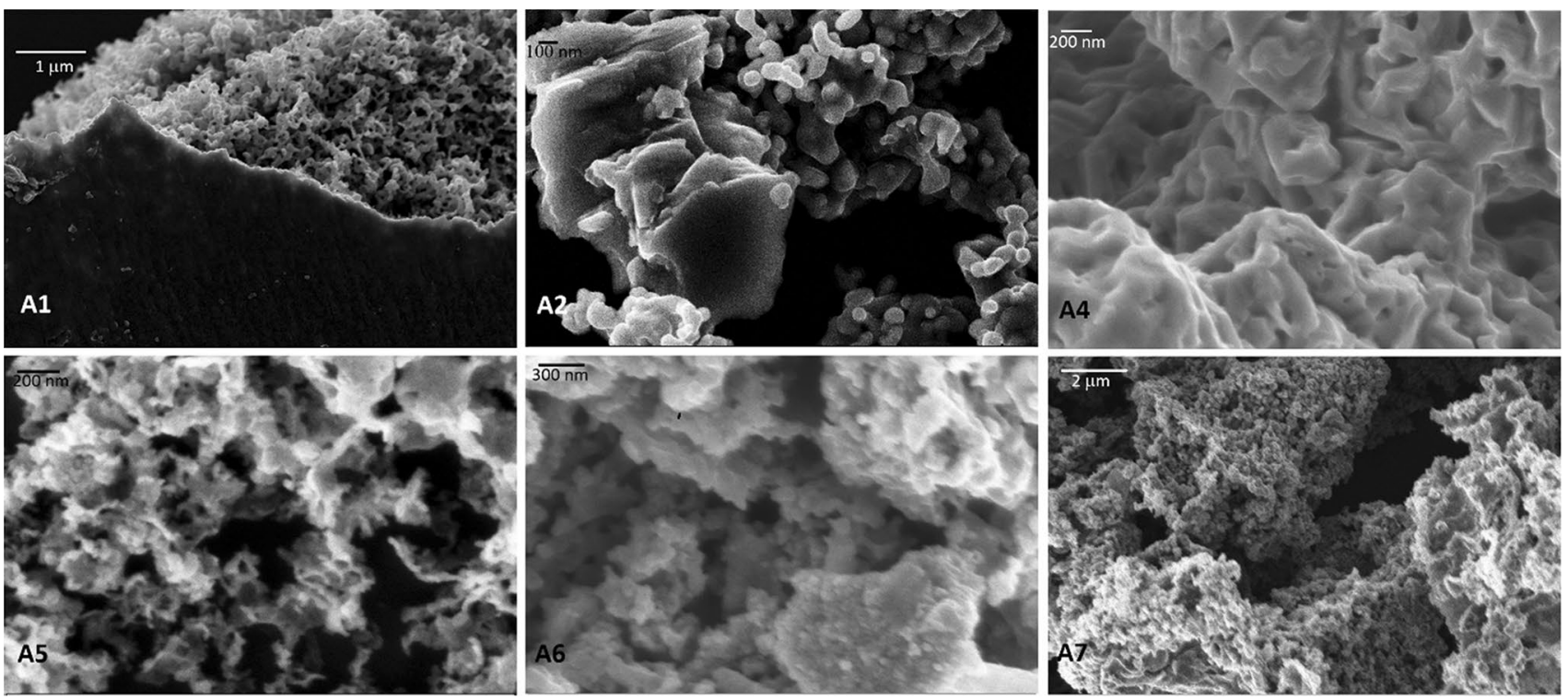

Fig. 2 SEM images of representative MN materials obtained by thermolysis of $\mathrm{MCl}_{3}(\mathrm{THF})_{3}$ under flowing ammonia

produced in this manner was typically a porous network composed of nanoparticles fused together, as evidenced by the SEM images (Fig. 2). BET data (Table 1) shows higher surface areas that correlate to lower thermolysis temperatures and shorter heating times, as expected. The difference between $\mathbf{A} \mathbf{2}$ and $\mathbf{A} \mathbf{3}$ is quite illustrative. Here, thermolysis at $900{ }^{\circ} \mathrm{C}$ for $2 \mathrm{~h}$ instead of $1 \mathrm{~h}$ produced VN with a much lower surface area, as the sintering of the grains is very time dependent, and the crystallite sizes increased modestly. The XPS data on $\mathbf{A} \mathbf{3}$ also shows probable nitrogen loss. Also, TiN is more refractory than $\mathrm{VN}$ and $\mathrm{CrN}$, and the BET data is consistent with this.

Since the goal was to generate individual nanoparticles and not macroscopic, albeit porous, materials, the synthesis was modified. Reaction of the $\mathrm{TiCl}_{3}(\mathrm{THF})_{3}$ precursor with 3 eq of $\mathrm{KNH}_{2}$ prior to thermolysis also produced porous materials composed of nanoparticles (B1), but adding oleylamine to that reaction (series $\mathbf{C}$ ) accomplished the goal of producing individual nanoparticles that were only moderately agglomerated. BET surface areas were high, ranging from 57 to $202 \mathrm{~m}^{2} / \mathrm{g}$, and the particle size calculated from BET was mostly consistent with the crystallite sizes determined by XRD, of which the powder patterns are shown in Fig. 3. While the preparations involving just Ti-N (C1), V-N (C3), and the mixture Ti-V-Cr-N (C2) showed just broad lines for the nitrides in their XRD patterns, the preparation of $\mathrm{Cr}-\mathrm{N}$ which was heated to intermediate temperatures of 200 and $450{ }^{\circ} \mathrm{C}$ (C4) showed evidence for carbides and carbonitrides, as well as chromium oxide. Apparently, carbonization occurred before the organics were thoroughly baked out. A repeat that was heated to intermediate temperatures of 250 and $350{ }^{\circ} \mathrm{C}$
(C5) lacked any peaks for those carbides or carbonitrides, but still showed the presence of $\mathrm{Cr}_{2} \mathrm{O}_{3}$. The origin of the oxygen in these products is unclear.

In order to maximize the light absorption of small TiN nanoparticles by avoiding their agglomeration and oxidation, they were in-situ deposited on a porous support. Gold nanoparticles were deposited in the same manner to serve as a reference (series $\mathbf{D}$ nanomaterials). We used a nonreactive support, porous $\gamma$-alumina, due to the complications presented by porous $\mathrm{TiO}_{2}$ (which is commercially available), but is reactive under a stream of flowing $\mathrm{NH}_{3}$ and presents issues that will not be discussed here. In these examples, the TiN was loaded into the support at about a $7 \mathrm{wt} \%$ concentration which

Method C -- High Surface Area NP's

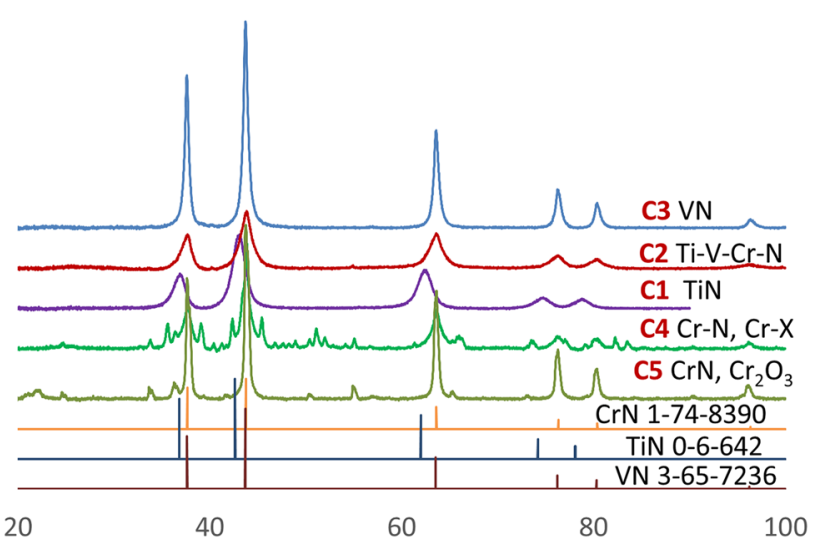

Fig. 3 XRD powder patterns of high surface area nanopowders, series $C$ 

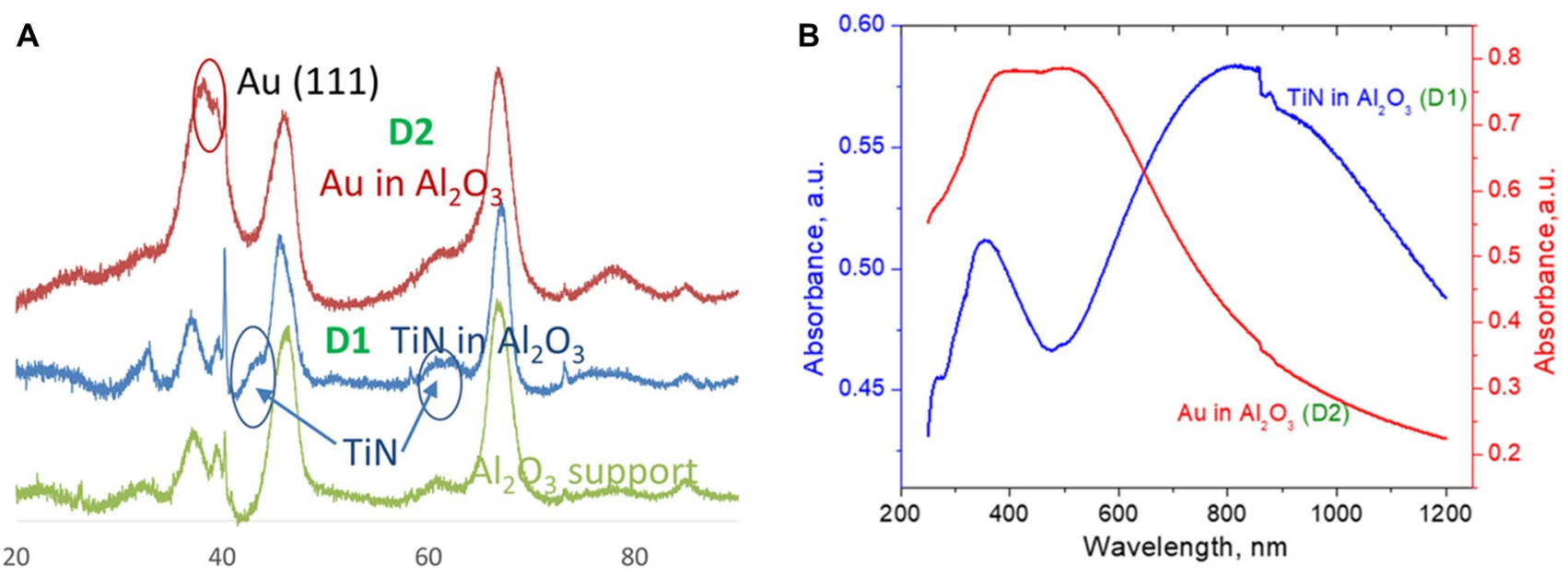

Fig. 4 a XRD powder patterns of the $\mathbf{D}$ series materials and the pure $\mathrm{Al}_{2} \mathrm{O}_{3}$ support for comparison. $\mathbf{b}$ Kubelka-Monk transformations of diffuse reflectance spectra of the $\mathrm{D}$ series materials recorded on $\mathrm{KBr}$ mixtures using an integrating sphere

represented the maximum amount of $\mathrm{TiCl}_{3}(\mathrm{THF})_{3}$ precursor that could be absorbed into the support. For the case of $\mathrm{Au}$, the $2 \%$ loading achieved here is probably nowhere near the maximum achievable, since the concentration of the stock $\mathrm{HAuCl}_{4}$ solution used was fairly low. While the XRD powder pattern of these materials shows evidence for the most prominent peaks of Au and TiN (Fig. 4a), those peaks are heavily obscured by reflections from the support and are not conclusive. Therefore we performed transmission electron microscopy (TEM) on these materials, which clearly show crystals of Au and TiN present due to morphology differences as well as intensity contrast, as seen in Fig. 5. These images show 3-4 nm cubic TiN and 20-30 nm spherical Au crystals. The small TiN nanocrystals are not agglomerated and evenly dispersed in the support.

All of the materials were analyzed by XPS for elemental composition, which is tabulated in the supporting information. For all materials, there is considerable oxygen and carbon on the surface, even in the $\mathbf{A}$ series, where the amount of carbon in the bulk should be much less, from stoichiometry and mass balance (yield) concerns alone. This is attributed to the fact that XPS is a surface, not a bulk, technique, and adventitious carbon and oxygen are present on nearly all materials. The cubic TiN crystal structure can be non-stoichiometric and can accommodate considerable substitution of nitrogen by carbon and oxygen, so the metal nitrogen ratios should be a better indicator of composition. These $\mathrm{M}: \mathrm{N}$ ratios for the $\mathbf{A}$ series are close to 1 except for $\mathbf{A} \mathbf{3}$ (V:N 1.89), which could be nitrogen deficient because it was heated for $2 \mathrm{~h}$ instead of $1 \mathrm{~h}$, and $\mathbf{A 5}$ (M:N 1.35) which also contains $\mathrm{V}$ and is nitrogen deficient. A1 and A5 contain potassium, which was not present in the starting materials and is thus attributed to surface contamination from the alumina boat or the quartz tube in which the reaction was done (as the reactions that did contain potassium were actually done before these two). The $\mathbf{C}$ series is all nitrogen deficient, and this is as expected since a lot of carbon is present in oleylamine. Residual potassium is present in most of the $\mathbf{C}$ series. In cases where multiple metals are present, the ratios approximately reflect the ratios of starting materials, except for $\mathbf{A 7}$, which is vanadium deficient. Apparently, when a solution of the $\mathrm{Ti}, \mathrm{V}$, and $\mathrm{Cr}$ salts crystallized from $\mathrm{CH}_{2} \mathrm{Cl}_{2}$, more of the $\mathrm{VCl}_{3}[\mathrm{THF}]_{3}$ remained in solution.

\subsection{Optical properties of materials}

Comparison of UV-Vis spectra displayed in Fig. 6 shows that our coarser VN (A2) and Ti-V-N (A5) nanoparticles dispersed in water exhibit a broad absorption maxima centered around $800 \mathrm{~nm}$. TiN (C1) nanoparticles dispersed in $\mathrm{H}_{2} \mathrm{O}$ demonstrate two rising branches extending to the left and right from $650 \mathrm{~nm}$, with no clearly pronounced absorption maximum. On the contrary, C1 particles dispersed in $\mathrm{CH}_{3} \mathrm{OH}$ demonstrate a clearly pronounced LSPR at $\sim 900 \mathrm{~nm}$. The absence of LSPR in water is likely due to oxidation and agglomeration of the ca $6 \mathrm{~nm}$ TiN nanoparticles. The strongest LSPR is observed for aqueous suspensions of $30 \mathrm{~nm}$ commercial TiN nanoparticles (Fig. 6b, green curve). The maximum centered at $700 \mathrm{~nm}$ is blue-shifted vs. those of $\mathbf{C 1} \mathbf{T i N}$ $\mathrm{NPs}$ in $\mathrm{CH}_{3} \mathrm{OH}$, and $\mathrm{VN}$ and Ti-V-N in $\mathrm{H}_{2} \mathrm{O}$. The red-shift and broadening of plasmonic resonances of $6 \mathrm{~nm} \mathrm{TiN}$, and $15 \mathrm{~nm}$ Ti-V-N NPs vs $30 \mathrm{~nm}$ TiN NPs is likely due to their stronger oxidation [23]. Diffuse reflectance spectra measured on $\mathrm{TiN} / \mathrm{Y}-\mathrm{Al}_{2} \mathrm{O}_{3}$ and $\mathrm{Au} / \mathrm{Y}-\mathrm{Al}_{2} \mathrm{O}_{3}$ powders 

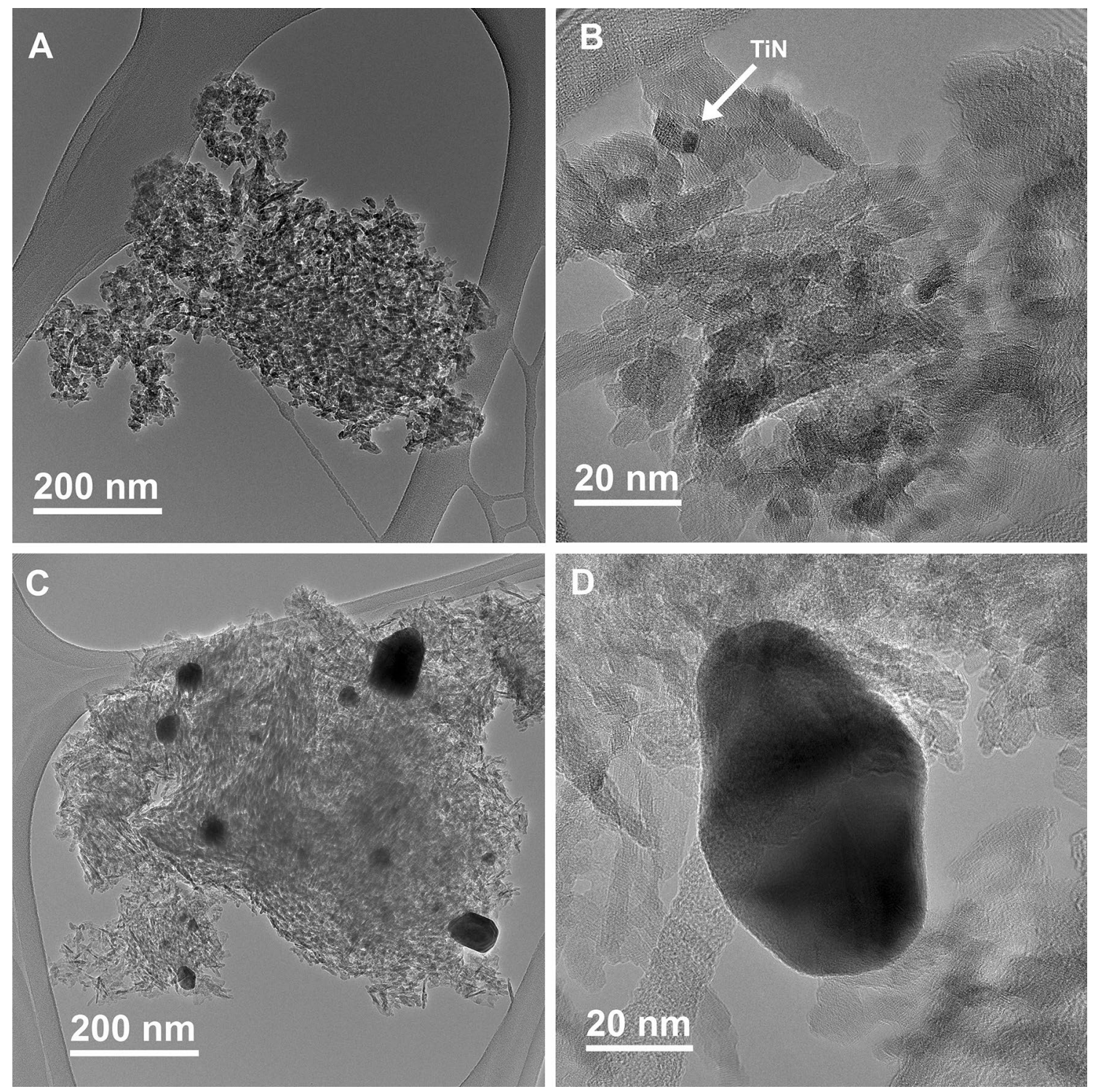

Fig. 5 TEM bright-field images of $\mathbf{D} 1\left(\mathrm{TiN} / \mathrm{Y}-\mathrm{Al}_{2} \mathrm{O}_{3}, \mathrm{~A}, \mathrm{~B}\right)$ and $\mathbf{D 2}\left(\mathrm{Au} / \mathrm{Y}-\mathrm{Al}_{2} \mathrm{O}_{3}, \mathrm{C}, \mathrm{D}\right)$. Images were obtained in a JEM2200FS TEM operating at $200 \mathrm{keV}$ with a One View electron camera

are depicted in Fig. 4b. A clearly pronounced absorption maximum at $\sim 800 \mathrm{~nm}$ is observed for $\mathrm{TiN} / \mathrm{Y}-\mathrm{Al}_{2} \mathrm{O}_{3}$ (D1). The maximum is $\sim 100 \mathrm{~nm}$ blue-shifted compared to its solution counterpart, probably due to the less pronounced agglomeration/oxidation of TiN nanoparticles, While less pronounced agglomeration of supported TiN nanoparticles is evident from Fig. 5, (D1), their less pronounced oxidation can be confirmed by comparison of corresponding Ti2p and N1s XPS spectra (SI). The least oxidized TiN nanoparticles are $30 \mathrm{~nm}$ commercial nanoparticles. For $\mathrm{Au} / \mathrm{\gamma}-\mathrm{Al}_{2} \mathrm{O}_{3}$ (D2), a broad maximum centered at $500 \mathrm{~nm}$ is observed. A close examinations shows two overlapping maxima centered at $\sim 520$ and $390 \mathrm{~nm}$. The first maximum is due to Au LSPR [1], while the second one is likely due to light absorption by the support.

Although a film-type morphology (produced in reaction $\mathbf{A} \mathbf{3}$ along with powder) is less useful for catalytic decomposition applications, which motivate our work, they do allow for direct measurement of the optical properties. These measurements will allow for prediction of plasmonic resonances and inform subsequent materials design and interrogation. The VN material produced a particularly well-behaved film suitable for ellipsometric measurement of optical properties. This material is metallic in some spectral regions and supports broad plasmonic resonances. We include the measured optical constants of our in-house synthesized VN, along with comparison to 

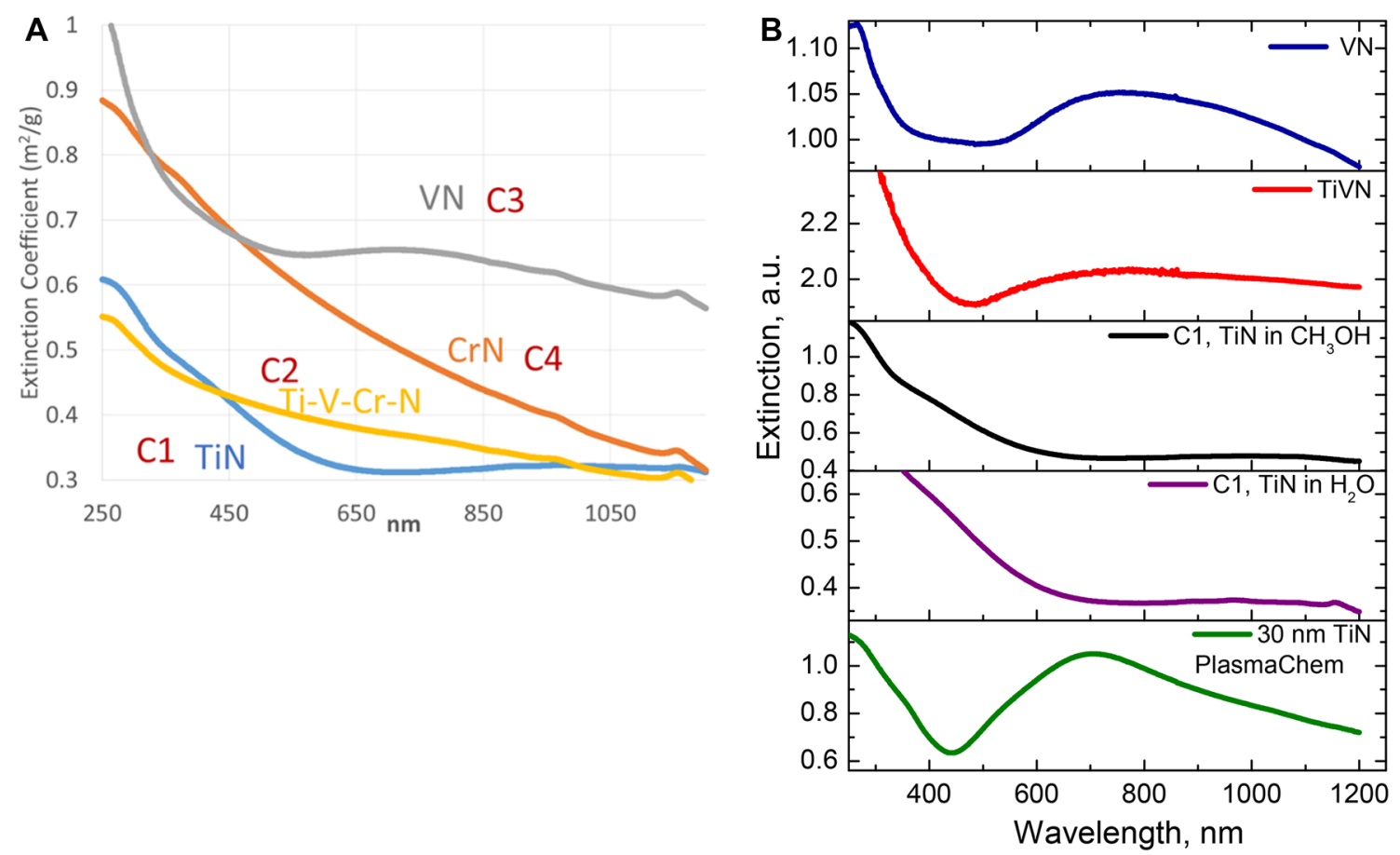

Fig. 6 a UV-Vis spectra of dispersions of C series nanomaterials in water. $\mathbf{b}$ A comparison of various nanomaterials in water and methanol with commercially available TiN nanoparticles (sold as $50 \mathrm{~nm}$, actual size $30 \mathrm{~nm}$ ) in water and methanol

Fig. 7 Chemical agent simulant Demeton-S (b) has both the P-S linkage similar to nerve agent $\mathrm{VX}(\mathbf{a})$ and the thioether linkage similar to vesicant $\mathrm{HD}$ (c)

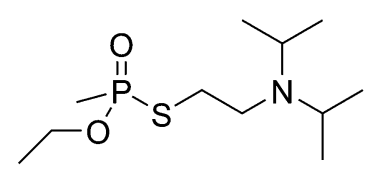

A<smiles>CCOP(=O)(OCC)SCCSCC</smiles>

B<smiles>ClCCSCCCl</smiles>

C two other literature examples, as well as predicted absorption spectra for this material in the $\mathrm{SI}$. The VN made in this work is comparable to data from the literature $[24,25]$ and shows a smaller value for the refractive index, $n$. We believe this is most likely due to some porosity of the material, which cause the measured value of $n$ to be between that of fully dense $\mathrm{VN}$ and of air. Additionally, while the material loss, $\mathrm{k}$, is comparable to the literature examples, it does become more absorptive at wavelengths above $\sim 750 \mathrm{~nm}$. These optical properties suggest that our VN should support optical resonances that, for a variety of aspect ratios, could span most of the visible spectrum (see SI). Assuming some distribution in particle aspect ratio, the measured extinction spectra in Fig. 6 are consistent with the optical measured by ellipsometry. We did not grow films of TiN by this method because TiN films have been sufficiently well studied, and the properties of our VN film was very consistent with previous reports.

\subsection{Chemical agent simulant decontamination challenge}

Demeton-S shown in Fig. 7b is utilized as a simple CWA simulant with the potential to investigate the reactivity of new active materials for decontamination [26-28]. Hydrolysis and oxidation relevant for organophosphate nerve agent VX (Fig. 7a) and/or vesicant sulfur mustard HD (Fig. 7c) can be investigated due to the presence of both a P-S bond and the thioether linkage in Demeton$S$ [29-34]. In addition to overall percent reduction of the simulant Demeton-S the analysis for and the identification of byproducts was also performed for understanding the chemical reactivity of these materials.

Preliminary screening experiments showed the TiN with the smallest nanoparticle sizes and highest surface area (C1) and the TiN impregnated in alumina (D1) to be the best materials to test for activity against Demeton-S. Percent reductions for the simulant challenges normalized to the mass of TiN and $\mathrm{TiN}-\mathrm{Al}_{2} \mathrm{O}_{3}$ in addition to control 
Table 3 Percent reduction of Demeton-S normalized to catalyst mass with respect to amount of simulant deposited

\begin{tabular}{lccc}
\hline $\begin{array}{l}\text { \% Reduction from con- } \\
\text { centration of simulant } \\
\text { deposited }^{\mathrm{a}}\end{array}$ & $\begin{array}{l}0 \mathrm{~h} \\
\text { expo- } \\
\text { sure (\%) }\end{array}$ & $6 \mathrm{~h}$ exposure (\%) & $\begin{array}{l}24 \mathrm{~h} \\
\text { exposure } \\
(\%)\end{array}$ \\
\hline Control-1 & 5.4 & 4.4 & 7.8 \\
Control-2 & 5.3 & $17.6^{*}$ & 6.9 \\
TiN-1 (C1) & 26.9 & 56.7 & 56.3 \\
TiN-2 (C1) & 33.4 & 53.0 & 59.3 \\
TiN-Al $\mathrm{O}_{3}$-1 (D1) & 25.3 & 38.6 & 38.6 \\
TiN-Al $\mathrm{O}_{3}-2$ (D1) & 16.0 & 37.0 & 42.4 \\
\hline
\end{tabular}

*Extraction inconsistent with others due to glass vial insert taper and enhanced capillary action resulting in an inconsistent extraction compared with other samples

${ }^{\text {a }}$ Stock solution prepared $10.5 \mu \mathrm{L}$ of Demeton-S $\left(4.66 \times 10^{-5} \mathrm{~mol}\right)$ in $2.0 \mathrm{~mL} \mathrm{CH} \mathrm{Cl}_{2}$. Deposition of $20 \mu \mathrm{L}$ stock solution $4.65 \times 10^{-7} \mathrm{~mol}$ applied Demeton-S. Catalyst masses presented in Table 2 challenges are shown in Table 3. The control challenges show consistent percent reductions between 4 and $8 \%$ indicating minimal loss of simulant during the challenge protocol. Inclusion of the $\mathrm{TiN}$ and $\mathrm{TiN}-\mathrm{Al}_{2} \mathrm{O}_{3}$ into the vial showed significantly improved decontamination performance for all challenge times including the $0 \mathrm{~h}$ exposures indicating that some simulant is readily sequestered on to the surface of the materials. Based upon the chromatographs in Fig. 8 and the percent reductions presented in Table 3 the reaction appears to have reached completion within $6 \mathrm{~h}$. The observation of less than $100 \%$ reduction is indicative that reactive species on the surface are responsible for the decontamination of Demeton-S which are potentially consumed or blocked after the reaction [30]. This hypothesis is supported by FTIR spectra of $\mathrm{KBr}$ pellets of the treated samples which show absorptions
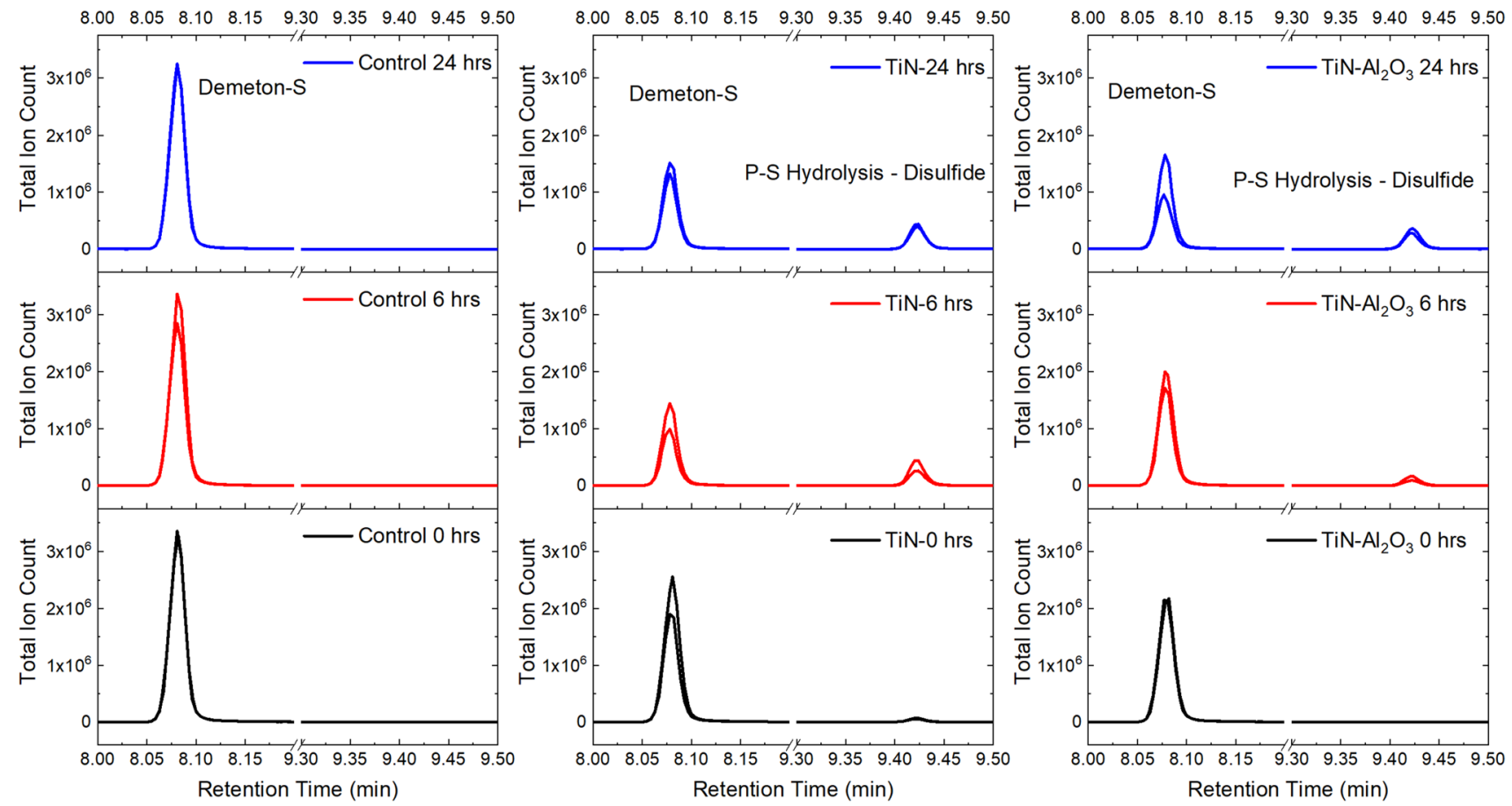

Fig. 8 Chromatograph stacks for control, $\mathrm{TiN}$ and $\mathrm{TiN}-\mathrm{Al}_{2} \mathrm{O}_{3}$ challenges. Each column shows the chromatograms at $0 \mathrm{~h}$ (bottom), $6 \mathrm{~h}$ (middle) and $24 \mathrm{~h}$ (top) for the control (left), TiN sample C1 (middle) and alumina impregnated TiN sample D1 (right) at a retention time of $8.08 \mathrm{~min}$ (Demeton-S) and the disulfide hydrolysis product at $9.42 \mathrm{~min}$. Each sample was analyzed in duplicate, and the chromatograms are superimposed. Additional data is shown in supporting information<smiles>CCOP(=O)(OCC)SCCSCC</smiles>

Fig. 9 Demeton-S hydrolysis reaction scheme via cleavage of the P-S bond. The disulfide is believed to form inside the hot inlet of the GC instrument 
for phosphate on samples treated with Demeton-S (supporting information). The observed reactivity differences between the two materials challenges is believed to be a result of surface area differences between the two materials. The TiN having a greater surface area has more reactive sites available for hydrolysis of the deposited simulant.

In addition to percent reduction the chromatography results in Fig. 8 show the presence of a byproduct at a retention time of $9.42 \mathrm{~min}$. Analysis of the mass spectrum fragmentation pattern (Supplemental Information) of the byproduct peak indicates hydrolysis of the P-S linkage of Demeton- $S$ to a thiol and subsequent $S-S$ coupling to the disulfide shown in Fig. 9. We believe this $S-S$ coupling is potentially taking place in the inlet of the GC instrument which is kept at $275^{\circ} \mathrm{C}$, as the hydrolysis reaction of organophosphate is consistent with previous reports which conducted analysis on similar materials $[30,35,36]$. The disulfide byproduct is present for both $\mathrm{TiN}$ and $\mathrm{TiN}-\mathrm{Al}_{2} \mathrm{O}_{3}$ materials and is consistent with the preferential reaction route for the decontamination of the organophosphate nerve agent VX with other hydrolytic agents [29-34]. Chromatographs for the TiN- $\mathrm{Al}_{2} \mathrm{O}_{3}$ products also show the presence of minor quantities of the thiol hydrolysis product with a retention time of $2.62 \mathrm{~min}$ (Fig. S5). The phosphate byproduct was not detected and is believed to be sequestered on the surface of the materials consistent with previous literature reports [30,35] and our IR measurements on the solids. We do not believe the hydrolysis is catalytic, but is instead a result of active $\mathrm{OH}$ groups in the material surface, which are then sequestered by the phosphate.

\section{Conclusions}

Nanoparticles of TiN, VN, and $\mathrm{CrN}$, and their solid solutions can be prepared effectively from the easily obtained metal trichloride-tri-THF precursors, and nanoparticles can also be easily grown inside a non-reactive support such as porous alumina. Materials made from direct nitridation of the precursor consist of a network of attached nanoparticles, while pre-reaction with $\mathrm{KNH}_{2}$ and oleylamine allows the synthesis of sub $10 \mathrm{~nm}$ particles in the bulk. The utilization of synthesized TiN and $\mathrm{TiN}-\mathrm{Al}_{2} \mathrm{O}_{3}$ show promise toward effective and preferential reactivity toward an organophosphate nerve agent simulant Demeton-S. The reactivity is not dependent on light exposure and thus is not a plasmonic effect. The hydrolysis of the P-S linkage in Demeton-S results in formation and detection of the disulfide and thiol hydrolysis products via GC-MS. Readily synthesized materials with tunable high surface area can find application as a reactive adsorbent material for active decontamination of threats while limiting the generation of hazardous waste from secondary emitters in post contamination scenarios.

Funding We thank the Office of Naval Research for financial support.

\section{Compliance with ethical standards}

Conflict of interest The authors declare no conflict of interest.

\section{References}

1. Baturina OA, Epshteyn A, Simpkins B, Bhattarai N, Brintlinger $T H$, Santiago EY, Govorov AO (2019) Comparing photoelectrochemical methanol oxidation mechanisms for gold versus titanium nitride nanoparticles dispersed in $\mathrm{TiO}_{2}$ matrix. J Electrochem Soc 166:H485-H493

2. Guler U, Boltasseva A, Shalaev VM (2014) Refractory plasmonics. Science 344:263-264

3. Guler U, Kildishev AV, Boltasseva A, Shalaev VM (2015) Plasmonics on the slope of enlightenment: the role of transition metal nitrides. Faraday Discuss 178:71

4. Naldoni A, Guler U, Wang ZX, Marelli M, Malara F, Meng XG, Besteiro LV, Govorov AO, Kildishev AV, Boltasseva A, Shalaev VM (2017) Broadband hot-electron collection for solar water splitting with plasmonic titanium nitride. Adv Opt Mater 5:1601031

5. Guler U, Naik GV, Boltasseva A, Shalaev VM, Kildishev AV (2012) Performance analysis of nitride alternative plasmonic materials for localized surface plasmon applications. Appl Phys B 107:285-291

6. Guler U, Ndukaife JC, Naik GV, Nnanna AG, Kildishev AV, Shalaev VM, Boltasseva A (2013) Local heating with lithographically fabricated plasmonic titanium nitride nanoparticles. Nano Lett 13:6078-6083

7. Exarhos S, Alvarez-Barragan A, Aytan E, Balandin AA, Mangolini $L$ (2018) Plasmonic core-shell zirconium nitride-silicon oxynitride nanoparticles. ACS Energy Lett 3:2349-2356

8. Wang F, Melosh NA (2011) Plasmonic energy collection through hot carrier extraction. Nano Lett 11:5426-5430

9. Narang P, Sundararaman R, Atwater HA (2016) Plasmonic hot carrier dynamics in solid-state and chemical systems for energy conversion. Nanophotonics 5:96-111

10. Malara F, Minguzzi A, Marelli M, Morandi S, Psaro R, Dal Santo $\mathrm{V}$, Naldoni $\mathrm{A}$ (2015) a- $\mathrm{Fe}_{2} \mathrm{O}_{3} / \mathrm{NiOOH}$ : an effective heterostructure for photoelectrochemical water oxidation. ACS Catal 5:5292-5300

11. Wang S, Gao Y, Miao S, Liu T, Mu L, Li R, Fan F, Li C (2017) Positioning the water oxidation reaction sites in plasmonic photocatalysts. J Am Chem Soc 139:11771-11778

12. DeSario PA, Pietron JJ, Dunkelberger A, Brintlinger TH, Baturina O, Stroud RM, Owrutsky JC, Rolison DR (2017) Plasmonic aerogels as a three-dimensional nanoscale platform for solar fuel photocatalysis. Langmuir 33:9444-9454

13. Li J, Cushing SK, Zheng P, Senty T, Meng F, Bristow AD, Manivannan A, Wu N (2014) Solar Hydrogen generation by a CdS$\mathrm{Au} . \mathrm{TiO}_{2}$ sandwich nanorod array enhanced with Au nanoparticles as electron relay and plasmonic photosensitizer. J Am Chem Soc 136:8438-8449

14. Yan L, Wang F, Meng S (2016) Quantum mode selectivity of plasmon-induced water splitting on gold nanoparticles. ACS Nano 10:5452-5458 
15. Sato $Y$, Naya S, Tada H (2015) A new bimetallic plasmonic photocatalyst consisting of gold(core)-copper(shell) nanoparticle and titanium(IV) oxide support. APL Mater 3:104502

16. DuChene JS, Tagliabue G, Welch AJ, Cheng WH, Atwater HA (2018) Hot hole collection and photoelectrochemical $\mathrm{CO}_{2}$ reduction with plasmonic $\mathrm{Au} / \mathrm{p}-\mathrm{GaN}$ photocathodes. Nano Lett 18:2545-2550

17. Zhou L et al (2018) Quantifying hot carrier and thermal contributions in plasmonic photocatalysis. Science 362:69-72

18. Knight MW, Sobhani H, Nordlander P, Halas NJ (2011) Photodection with active optical antennas. Science 332:702-704

19. Ahn W, Vurgaftman I, Pietron JJ, Pehrsson PE, Simpkins BS (2019) Energy-tunable photocatalysis by hot carriers generated by surface plasmon polaritons. J Mater Chem A 7:7015-7024

20. Jones NA, Liddle ST, Wilson C, Arnold PL (2007) Titanium(III) Alkoxy-N-heterocyclic Carbenes and a safe, low-cost route to $\mathrm{TiCl}_{3}(\mathrm{THF})_{3}$. Organometallics 26:755-757

21. Manzer LE (1982) TRICHLOROTRIS(TETRAHYDROFURAN) VANADIUM(III), $\mathrm{VCl}_{3}(\mathrm{THF})_{3}$. Inorg Synth 21:138

22. Herwig W, Zeiss HH (1958) Chromium trichloride tetrahydrofuranate. J Organic Chem 23:1404

23. Barragan AA, llawe NV, Zhong L, Wong BM, Mangolini L, J. (2017) A Non-thermal plasma route to plasmonic TiN nanoparticles. Phys Chem C 121:2316-2322

24. Pflüger J, Fink J, Weber W, Bohnen KP, Crecelius G (1984) Dielectric properties of $\mathrm{TiC}_{\mathrm{x}}, \mathrm{TiN}_{\mathrm{x}}, \mathrm{VC}_{\mathrm{x}}$, and $\mathrm{VN}_{\mathrm{x}}$ from 1.5 to $40 \mathrm{eV}$ determined by electron-energy-loss spectroscopy. Phys Rev B 30:1155-1163

25. Gueddaoui H, Maabed S, Schmerber G, Guemmaz M, Parlebas JC (2007) Structural and optical properties of vanadium and hafnium nitride nanoscale films: effect of stoichiometry. Eur Phys J B 60:305-312

26. Giles SL, Lundin JG, Balow RB, Pehrsson PE, Wynne JH (2017) Comparative roles of $\mathrm{Zr}^{4+}$ and $\mathrm{Ni}^{2+}$ Wells-Dawson hetero-metal substituted polyoxometalates on oxidation of chemical contaminants. Appl Catal A 542:306-310

27. McGann CL, Daniels GC, Giles SL, Balow RB, Miranda-Zayas JL, Lundin JG, Wynne JH (2018) Air activated self-decontaminating polydicyclopentadiene polyhipe foams for rapid decontamination of chemical warfare agents. Macromol Rapid Commun 39(12):1800194
28. Balow RB, Giles SL, McGann CL, Daniels GC, Lundin JG, Pehrsson PE, Wynne JH (2018) Rapid decontamination of chemical warfare agent simulant with thermally activated porous polymer foams. Ind Eng Chem Res 57(25):8630-8634

29. Roberts G, Maynard RL (2007) Responding to chemical terrorism: operational planning and decontamination. In: Marrs TC, Maynard RL, Sidell FR (eds) Chemical warfare agents: toxicology and treatment, 2nd edn. Wiley, West Sussex, pp 175-190

30. Bandosz TJ, Laskoski M, Mahle J, Mogilevsky G, Peterson GW, Rossin JA, Wagner GW (2012) Reactions of VX, GD, and HD with $\mathrm{Zr}(\mathrm{OH})_{4}$ : near instantaneous decontamination of VX. J Phys Chem C 116(21):11606-11614

31. Talmage SS, Munro NB, Watson AP, King JF, Hauschild V (2007) The fate of chemical warfare agents in the environment. In: Marrs TC, Maynard RL, Sidell FR (eds) Chemical warfare agents: toxicology and treatment, 2nd edn. Wiley, West Sussex, pp 89-125

32. Wagner GW, Yang Y (2002) Rapid nucleophilic/oxidative decontamination of chemical warfare agents. Ind Eng Chem Res 41:1925-1928

33. Wagner GW, Sorrick DC, Procell LR, Brickhouse MD, Mcvey IF, Schwartz LI (2007) Decontamination of VX, GD, and HD on a Surface using modified vaporized hydrogen peroxide. Langmuir 23:1178-1186

34. Yang Y, Baker JA, Ward JR (1992) Decontamination of chemical warfare agents. Chem Rev 92:1729-1743

35. Wagner GW, Procell LR, O'Connor RJ, Munavalli S, Carnes CL, Kapoor PN, Klabunde KJ (2001) Reactions of VX, GB, GD, and HD with Nanosize $\mathrm{Al}_{2} \mathrm{O}_{3}$. Formation of aluminophosphonates. J Am Chem Soc 123:1636-1644

36. Balow RB, Lundin JG, Daniels GC, Gordon WO, Mcentee M, Peterson GW, Wynne JH, Pehrsson PE (2017) Environmental effects on zirconium hydroxide nanoparticles and chemical warfare agent decomposition: implications of atmospheric water and carbon dioxide. ACS Appl Mater Interfaces 9:39747-39757

Publisher's Note Springer Nature remains neutral with regard to jurisdictional claims in published maps and institutional affiliations. 